191 - got recommendations for medical application with special indications; 108 - did not get such recommendations because of the absence of the reliable clinical information about the safety, 50 of them are not recommended for medical application, because of their toxicity. Among the medicinal plants, which are not recommended for the medical application by commission, there are some traditional medicinal plants in Russian herbal medicine as such Inula helenium, Angelica arch- angelica, Calendula officinalis, Tussilago farfara, Avena sativa, Paeonia officinalis, Silybum marianum. Published materials of the commission $E$ are formulated as recommendations, but in fact they have regulatory character. Comission $\mathrm{E}$ have paid special attention to diminish the treatment time for some plants with potential toxicity. So, drugs, produced from the natural raw materials, demand the thorough studying with the aim to support the safety of the patients.

\title{
BIOLOGICAL ACTIVE PREPARATIONS FROM HYDROBIONTS
}

\section{(C) Shikov Alexander N., Pozharitskaya Olga N., Makarova Marina N., Makarov Valery G.}

\author{
St-Petersburg Institute of Pharmacy, 47/5, Piskarevsky prosp., 195067, St-Petersburg, Russia
}

The biodiversity of the marine environment and the associated chemical diversity constitute a practically unlimited resource of new bioactive substances. Hydrobionts are living in a very exigent, competitive, and aggressive surrounding which demands the production of quite specific and potent active molecules. Search for new anti-inflammatory, anti-allergic, anti-viral, antibacterial, antihypertensive, immunomodulatory, reparative, cytoprotective etc. substances and methods for their isolation are priorities in the study of hydrobionts. The objects of research are fish, sea urchins, gastropods, krill and other crustaceans, corals and algae. Peptides, polysaccharides, fatty acids, enzymes, vitamins and minerals are the most common isolated active principles. Common methods of processing of hydrobionts are focused in isolation of exact group of active substances. However complex processing of marine organism is open broad perspectives in development of new preparations. Chinoid pigments, chitosan, salts of organic $\mathrm{Ca}$, peptides complex, phospholipids, enzy- matic complex were isolated in results of complex processing of sea urchin. Lipid and hydrophilic complexes were extracted from cod liver. Polyhydroxylated naphtoquinone pigments isolated from sea urchins shells were able to scavenge $\mathrm{DPPH}^{\cdot}$ with $\mathrm{ID}_{50}=0.043-0.057 \mu \mathrm{g}$ according to HPTLC-DPPH test. Pigments in dose of $100 \mu \mathrm{g} / \mathrm{ml}$ have inhibited the grooving of Candida albicans. Peptide-amino acid complex from sea urchin was effective in the treatment of acute rhinosinusitis of rats and showed immunosuppressive properties in mice. The complex of peptides associated with phospholipids from cod liver was studied as anti-inflammatory, reparative and anti-allergic agent for veterinary praxis. Extract of coelomic fluid of sea urchin showed anti-inflammatory and anti-hyaluronidase activity. Sexual activity of rats was increased after single administration of special fraction of sea urchin and mobility and survival was increased after 8 weeks of administration. Hydrobionts are potent sources of biological active compounds with the wide specter of pharmacological activity.

\section{STUDY OF PHARMACOLOGICAL ACTIVITY OF STRONGHYLOCENTROTUS DROEBACHIENSIS EXTRACT ON THE ERECTILE FUNCTION OF YOUNG ADULT MALE WISTAR RATS}

\section{ㄷ Shubin D. V., Ivanova S. A., Makarova M. N.}

Saint-Petersburg Institute of Pharmacy, Russia

Marine natural products have attracted the attention of biologists and chemists of the world over for the last five decades. The gonads of the sea urchins (Stronghylocentrotus droebachiensis) have many types of bioactive compounds and are the good source of pharmacological agents designed to correct disorders of a sexual health of men. The aim of the study was to assess the pharmacological activity of Stronghylocen- trotus droebachiensis extract on the erectile function of young male adult Wistar rats. The Stronghylocentrotus droebachiensis extract was administered per os in doses $1.3,6.4$ and $12.8 \mathrm{mg} / \mathrm{kg}$. There were used two schemes of the experiment: single administration with the reference drug Viagra (sildenafil citrate) (Pfizer, France) and multiple administration during 60 days with the reference drug of plant origin Tentex forte (Himala- 
ya, India). To evaluate the rat erectile function following parameters of male sexual behaviour were examined: latent periods, the intromission frequency, copulatory efficiency, latent period of ejaculation, the number of ejaculations and post-ejaculatory interval. Also, testosterone, NO blood plasma levels, and blood pressure were measured. It was obsereved that the single administration of the tested extract in a dose $12.8 \mathrm{mg} / \mathrm{kg}$ significantly reduced the latent periods. The repeated administration of Stronghylocentrotus droebachiensis extract during 60 days led to copulatory efficiency and the number of ejaculations increasing. The tested extract had the same pharmacological activity compared to the reference drugs. Thus, the results of the study shown that Stronghylocentrotus droebachiensis extract can be regarded as the natural origin drug with the good aphrodisiac effects to improve male erectile function.

\section{ROLE OF HERBAL OSTEOGENIC AGENTS IN MANDIBULAR FRACTURE - A STUDY}

\section{(c) Singh Vibha, Singh Narendra}

Department of Oral and Maxillofacial Surgery, C. S. M. Medical University Lucknow, India Director -International Institute of herbal Medicine, International Society for Herbal Medicines, India

Fractures of the jaw bones renders not only physical trauma but al so makes the person missout on work productivity and other social obligations for a period ranging from 4-8 week on an average. Ayurveda the ancient science system of the medicine describes various herbs preparation that achieves the hastening of bone healing. The Cissus quadrangularis stimulates osteogenesis (1-3). Cissus quadrangularis (family Vitaceae) a rambling shrub, characterized by a thick quadrangular fleshy stout stem commonly known as "Bone setter" the plant is referred as "Asthisamdhani" in Sanskrit and Hadjod in Hindi because of its ability to join bones (2). In this study we included 30 patients of trauma who reported to the department of Oral and Maxillofacial Surgery. They were treated by close reduction and divided in to two groups: Group 1 - Patients were given 2 capsules of Cissus quadrangularis twice a day for 6 weeks; Group 2 - Patients were given 2 capsules of Placebo (Starch capsules), twice a day for 6 weeks. Before administration of medications, written consent was taken and every possible complications were explained. Through clinical, radiological, biochemical and hematological profile was carried out. Subsequent investigations were carried out during follow up periods. Results were assessed on the basis of clinical hematological, biochemical radiological finding at $1^{\text {st }}, 3^{\text {rd }}$ and 6 weeks and on the $3^{\text {rd }}$ month follow up., based on the following parameters, pain, swelling, mobility between fragments, bite force recording, OPG, Serum calcium, Serum phosphate, Alkaline phosphatase, and Osteopontin (4). There was significant reduction in pain, swelling, mobility in group 1. Bite force showed increasing value at subsequent follow-up corresponding to early healing in group 1. All the observation proved that Hadjor (Cissus quadrangularis) accelerates fracture healing.

References: (1) Deka D K, Lahon LC. Effect of Cissus quadrangularis in accelerating healing process of experimentallyfractured radius-ulna of dog, A preliminary study. Indian $J$ of Pharmacology 1994, 26: 44-45. (2) Narendra Singh \& Marilena Gilca (2010) Herbal Medicine Science Embraces Tradition - A new insight into ancient Ayurveda. Lambert Publisher, Germany. 233pp. (3) Parisuthiman D, Singhatanadgit W, Dechatiwongse T, Koontongkaew S. Cissus quadrangularis extract enhances biomineralization through up-regulation of MAPK-dependent alkaline phosphatase activity in osteoblasts. In Vitro Cell Dev Biol Anim 2009, 45: 194-200. (4) Denhardt DT, Noda M. Osteopontin expression and function: role in bone remodeling. J Cell Biochem Suppl. 1998, 30-31: 92-102. 